\title{
The Effectiveness of Outdoor Advertising Influenced by Urban Environment Factors to Art, Economy and Society in Vietnam
}

\author{
Nguyen Thi Viet Ha \\ Vietnam Art Design Faculty, University of Architecture Ho Chi Minh City, Ho Chi Minh City, Vietnam \\ Email address: \\ ha.nguyenthiviet@uah.edu.vn \\ To cite this article: \\ Nguyen Thi Viet Ha. The Effectiveness of Outdoor Advertising Influenced by Urban Environment Factors to Art, Economy and Society in \\ Vietnam. Urban and Regional Planning. Vol. 4, No. 1, 2019, pp. 9-15. doi: 10.11648/j.urp.20190401.12
}

Received: February 25, 2019; Accepted: April 4, 2019; Published: May 7, 2019

\begin{abstract}
The goal of research is urban environment factors have positive impacts on the aesthetics of outdoor advertising, contribute to these values: in terms of art (creating a new vision and conception of artistic creation); in the aspect of society (meeting the needs of enjoyment of the public at present time); and in economic terms (contributing to the development of the economy). In the era of International Integration of Vietnam, the outdoor advertising influenced by Urban Environment factors plays a very important role in a large number of changes in advertising. Especially in Ho Chi Minh City where there is a diversity of market trends and also a place which is greatly and quickly influenced by new trends in Art and Design. This is also considered as the place that can absorb quickly new trends of Arts and Culture. Besides, the city also plays as the leader in creating Advertising campaigns for Vietnamese market.
\end{abstract}

Keywords: Urban Environment, Smart Community, Outdoor Advertising, Effectiveness of Advertising, Visual Communication, Poster, Artistic Creativity's Concepts, Development of the Economy

\section{Introduction}

Outdoor advertising is an important part in graphic design and contributes considerably to the "green industry" - the modern advertising industry. Urban environment factors have given special attention, and have even become a trend, spreading to the art of design, particularly in outdoor advertising in Ho Chi Minh city ${ }^{1}$. Especially in visual communication elements, from concept to execution. That can absorb quickly new trends of arts and culture in creating advertising campaigns of modern society. In terms of outdoor advertising' characteristic, the aesthetics cannot be distinguished from the non-aesthetics in researchs because the shortage of dometic research on graphic design. In order to make it clear, the research should focus not only the meaning itself but also on contents and form in living environment, which make an artwork more valuable [1].
The audiovisual technology has created many different forms, design methods of advertising, also known as multimedia communications. This is thoroughly exploited for advertising and marketing purposes. One of the most effective forms of marketing advertising today is outdoor advertising of smart community. In other words, it is a very important marketing strategy that businesses want to take advantage of.

All the manifestations are considered for the targeted marketing, the integration of the communication in every advertising strategy is always highly appreciated. That may draw out some values to prove that the environment, real life elements contribute to art, economy and the society. 


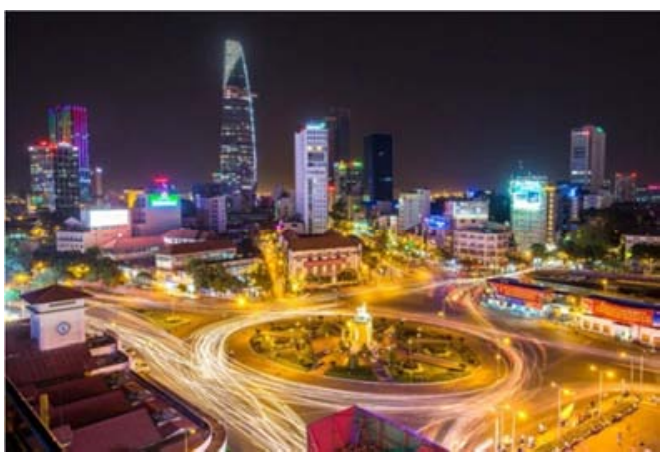

Figure 1. Ho Chi Minh City is a great starting point for any brand manager looking to enter the Vietnam market with a population over 9 million. "Ho Chi Minh City (HCMC) is witnessing a dynamic phase of economic growth, industrial expansion and land use change which is transforming the city's fortunes and attracting business opportunities" [9].

\section{Source of photo:}

https://www.siemens.com/press/en/presspicture/?press=/en/presspicture/201 4/corporate/im2014110148coen.htm\&content[]=Corp (8:50 AM, 20 april 2019)

\section{Outdoor Advertising Influenced by Urban Environment Factors Contributes to Change the Artistic Creativity's Concepts}

The young advertising design of Vietnam appeared when the European advertisement had already reached to their peak (flourished at the end of the 20th century), along with the advanced development of technology, science and technique, it had contributed to the appearance of outdoor advertising in the competition of the commercial market in the open - trading period. From the approaching, explanation to the practice of art creativity in general and particularly in advertising; there is new perspective that reflects the new reality of the world according to the urban environment elements' characteristics, such as:

Firstly, urban environment factors are the harmonious combination of the traditional stereotypes and artistic methodology, and the expanding new concepts of art. Outdoor advertising have strongly transformed all the urban environment elements become Vietnamese, creating aesthetic in the combination of tradition and modern, East and West.

At the moment, outdoor advertising is more liberal, which goes beyond the concept of visualization on a surface. For example, with the traditional two-dimensional design, the designs are printed only on rectangular areas, and are hung or glued to certain locations. This also creates a boredom due to mass production and stereotyping [2]. Modern outdoor advertising, instead, is designed based on greater attention to urban space and interaction with the environment (installation art way). Moreover, the public could also be involved in artworks. These ideas somehow have helped to extend the spatial dimension of traditional two-dimensional design, not just three dimensions but also spatial patterns and in specific contexts [3].
As a matter of fact, the new urbanization has affected the change of outdoor advertising. Evidence is that there are new manifestations, new skills and new interaction between outdoor advertising, arts and other fields. These commonly changes are increasing significantly and strongly influence the advertising market in Vietnam nowadays. This is a process of redirecting the concept of arts in creation and enjoyment of artworks in Vietnam. It is considered to be of great significance in the development of graphic design, especially in the field of visual communication.

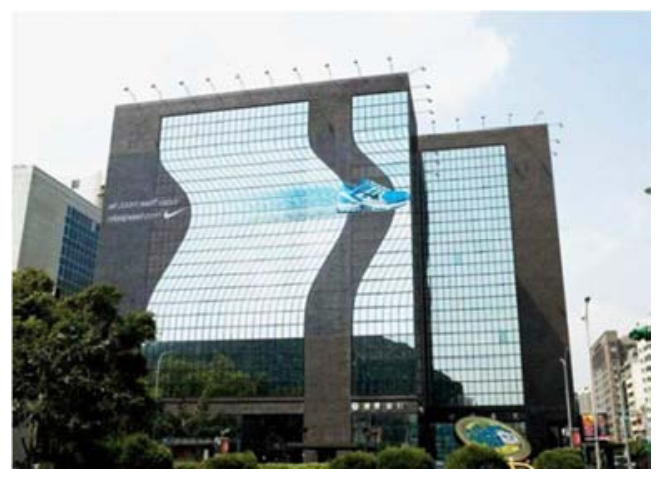

Figure 2. Example, Nike sport advertising on building. "Nike Tennis Shoes Building Advertisement: A clever ad which demonstrates how fast you can run with Nike tennis shoes". Strangest buildings from advertising, which the rigidity of the building was deformed by advertising work [10].

Source of photo:

https://www.crookedbrains.net/2010/04/building-advertisements.html (8:42AM, 28 April 2019)

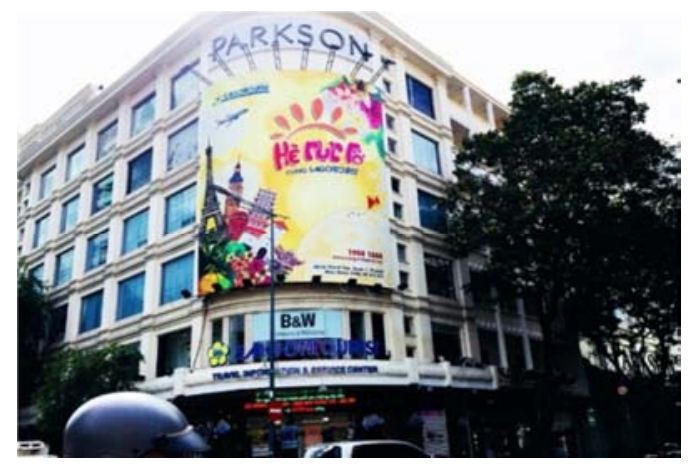

Source of photo: Author, 20/7/2018

Figure 3. Building wraps are giant almost billboard-like advertisements that are attached to buildings in order to catch the attention of an audience. Example, Saigontourist utilizes the corner of the building available to advertising in District 1, Ho Chi Minh City, Vietnam

Second, urban factors are the diversification of the creation's methods associated with the need of the market economy and the reflection of the targeted viewers. Designing outdoor advertising is the harmonious mixture of the analytical thinking, reasoning and emotion, commercial and aesthetic, fusion and distinction, creative personality and nationality's characteristic, perfectionizing the profession.

In addition, changes which are influenced by the urban environment help designers become more professional. Undeniably, the design is dominated by a mixture of advertisers, designers, producers and the public. As a result, 
advertisers are not only academically skillful but also knowledgeable about marketing and culture. Besides, they need to know how to make the most of space in the urban environment and grasp the technology trend. In this way, they will be more nimble in creation, which makes their designs more effective. Outdoor advertising is most common in advertising strategies, from long-term, medium-term to short-term strategies as well as from emotional to rational marketing [4]. Depending on diferent advertising strategies, designers will have various ways of exploiting the different urban environmental factors in order to make the most out of effective outdoor advertising.
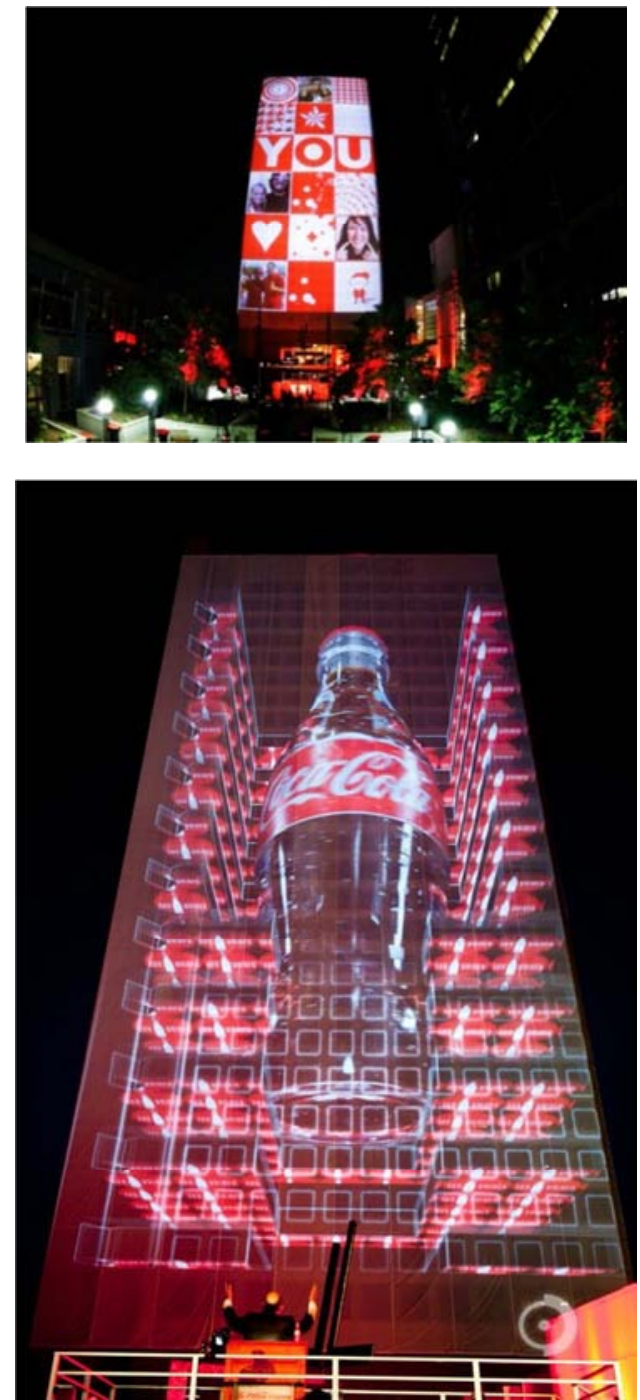

Figure 4. Visual communication makes the urban space change. Example, Coke advertising on building with digital technology effects. "Coca Cola is celebrating 125 years in business in style with a spectacular building illumination featuring some of the most amazing Coca-Cola moments of the past 125 years. The multimedia display features a high-resolution cinematic show reaching 26 stories high on all four sides of the Coca-Cola Tower at their headquarters in Atlanta, GA". The building becomes a visual art work between the urban place [11].

Source of photo:

http://theinspirationroom.com/daily/2011/coca-cola-illuminates-125-years/ (8:35 AM, 28 April 2019)
Additionally, in terms of advertising, the scope of interaction that outdoor advertising presents is enormous. This partly because of the practical of life extends the boundary of some types of outdoor advertising. In the past, different types of outdoor advertising were clearly distinguished. Today, however, they are relatively categorized. Besides, they are in mutual relationship because the common goal is to engage into mass communication such as TVC advertising, 2D printing, multimaterial printing, ect. The advantage of this is that it helps diversify outdoor advertising, which meets the needs and extends the periphery of advertising. Similarly, it's no longer just hanging or pasting but also has the function of a backdrop. Moreover, it is not only used for advertising contents but also for displaying and entertainment purposes.

In recent years, advertising activities in Vietnam have developed rapidly. In fact, it shows that the application of information technology achievements shortens the distance to world knowledge. As a result, new design trends around the world have been promptly adopted in Vietnam. As a result, new design movements around the world have been quickly implemented in Vietnam. The Vietnamese designers have been flexible in bringing urban environment elements into their designs, which helps them integrate into the new era. Especially, outdoor advertising has made a lot of significant variations in the context of the urban environment.

In additions, it can be said that technology has changed and shaped the high aesthetic demands in society. Many details in design have been standardized by technology and become the important language of designers in the manufacturing process. As a matter of fact, until the 2000s, typical designs were only manual arts, manual works which being drawn on papers, fabrics, metal sheets ect. However, in the last 20 years, computers, softwares, and machinery have changed the way advertising works. The concept of "digital design" has started to make a new trend in outdoor advertising. In particular, the current design softwares allow the creation of images to be "transformed" quickly, accurately and sharply.
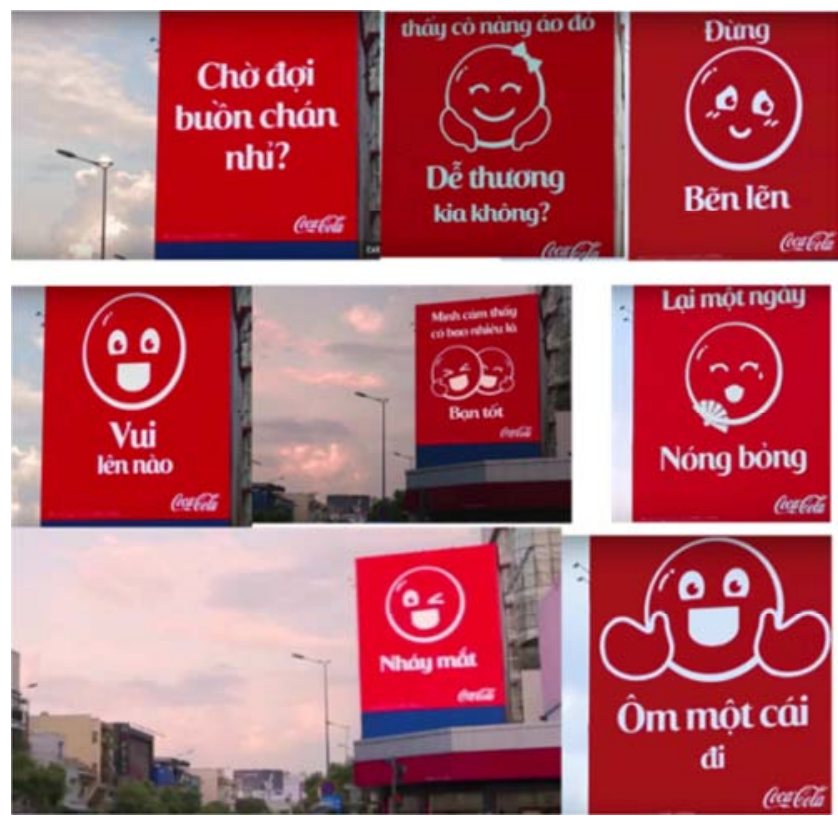


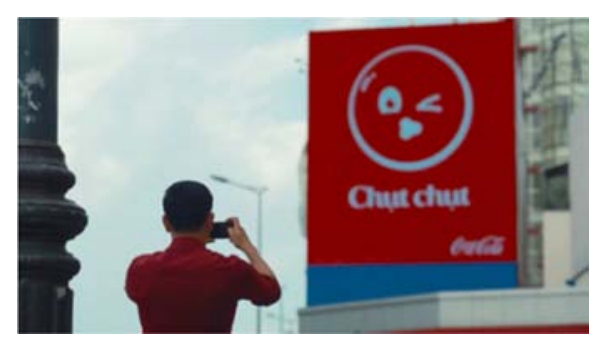

Figure 5. Advertising for a business has changed drastically over the last years in Ho Chi Minh City, the focus is more on the technology and design method more than anything else, fast-paced advertising campaigns with modern trend. Example, advertising "speak" of Coke on Nguyen Van Troi Street, HoChiMinh City, Vietnam [12].

\section{Source of photo:}

https://news.zing.vn/video-bang-quang-cao-biet-noi-doc-dao-post562072.ht $\mathrm{ml}$ (9:00 AM, 16 May 2017)

Thirdly, it is the flexibility of mixing urban environment elements that transfer outdoor advertising from its original form. They highlight social values, community, and art symbol. This is the shift of ideology [5]. Nowadays, most of advertising choose a level of specific characteristics and methods, which has urban envirnment elements to apply in order to make good effects in creating an artwork.

More than that, in a multicultural and intellectual environment, outdoor advertising nowadays is not just a "monologue" but a "dialogue". Fine art is now a catalyst, evoking emotions for the public. Therefore, art needs a tendency that is diverse enough to satisfy the varied needs of human aesthetics [6].

In general, as being an artwork that was formed from the needs of human life or to be precise, it is the commercial needs, outdoor advertising is different from the trend of creating art as "art for art's sake"- the artist only creates an artwork because of his/her own emotion or for the sake of art [7]; on the contrary, the policy of designing artists in the field of applied arts is " art for life's sake" - which means that art must connect closely to life, serve human, and have a specific purpose.

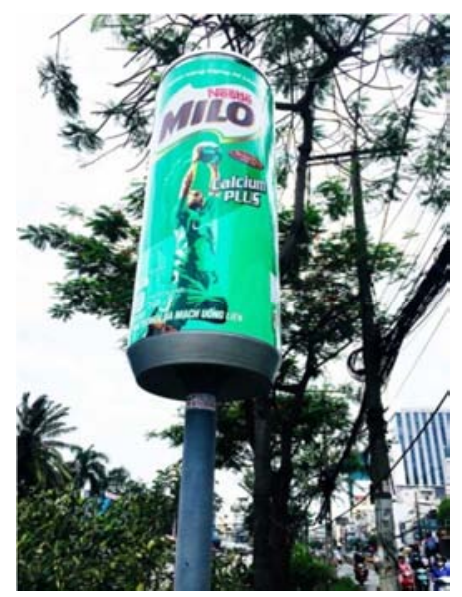

Source of photo: Author, 20/7/2018

Figure 6. Milo used the urban space and visualization technology to image promotion in District 10, Ho Chi Minh City, Vietnam. Create giant milk cans along the street, that is an impression on the public.

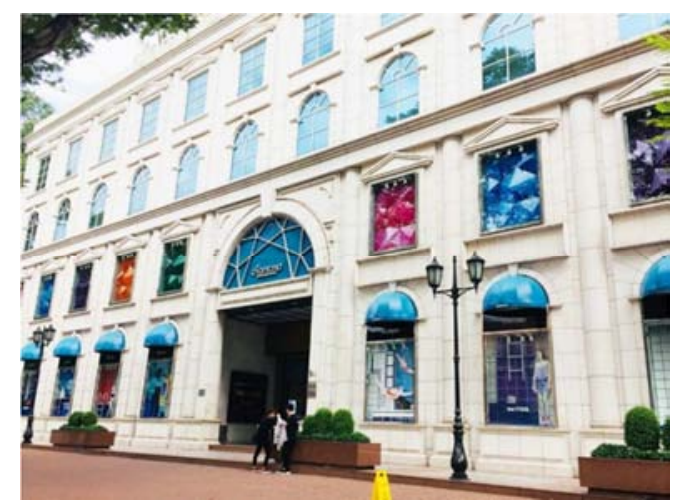

Source of photo: Author, 20/7/2018

Figure 7. Display window is a way to promote, it use the art of installatuon. Most of the main materials are promotional products. Example, Diamond plaza in District 1, Ho Chi Minh City, Vietnam. Create giant milk cans along the street, that is an impression on the public.

\section{Outdoor Advertising Influenced by Urban Environment Factors Contributes to Impulse the Development of the Economy}

Advertising user is an important factor in the change of outdoor advertising. It means that the awareness of those businesses participated in an advertisement have made decisions on aesthetic values of advertising; and conversely, outdoor advertising have changed the aesthetic awareness of Vietnamese enterprises nowadays.

Remarkably, outdoor advertising users have make environment factors expand such as: changing their desires, having new perspective in the idea's expression of advertising, actively finding a creative way to break the old form order, finding new ones. They emphasize on the design requirement that it has to be different from the traditional style to attract customers because they think "beautiful design makes business flourish".

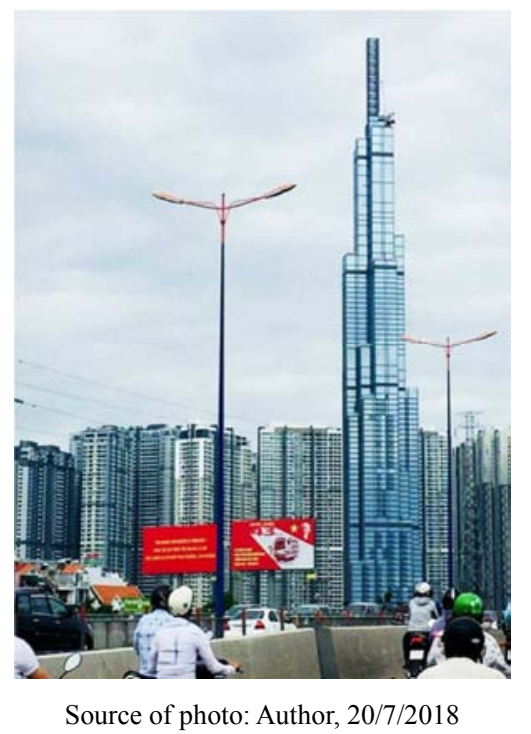

Figure 8. In District 2, Ho Chi Minh City, Vietnam. 
Additionally, the combination between outdoor advertising and urban environment is a powerful tool in competitive businesses. It is undeniable that in market economy, competition contributes to profitability. Brands need a unique personality, strategy, and a different way of communicating. This helps them to easily compete with their opponents. In that context, outdoor advertising, which is dynamic and sensitivity, created not only a special business but also the close connection between businesses and consumers.

For this reason, outdoor advertising designs with fascinated ideas, creative and attractive expressions are always available for designers [6]. Only when designs are inseparable from the urban environment, the brand's products can attract people's attention. This stimulates consumption and thus promotes market economy development.

Generally, outdoor advertising is the combination of aesthetic value and economic term, in other way, the success of outdoor advertising based on two core factors that cannot be separate which are function and aesthetic. The aesthetics of outdoor advertising is valuable when it satisfies the business' purpose and has economy efficiency [5]. In the era that science and technology have reached its peak, while the differences in technical quality, ground costs and raw materials are all the same, artistic value will become the first element to compare and it is a needed factor to promote business and to compete in the market today.
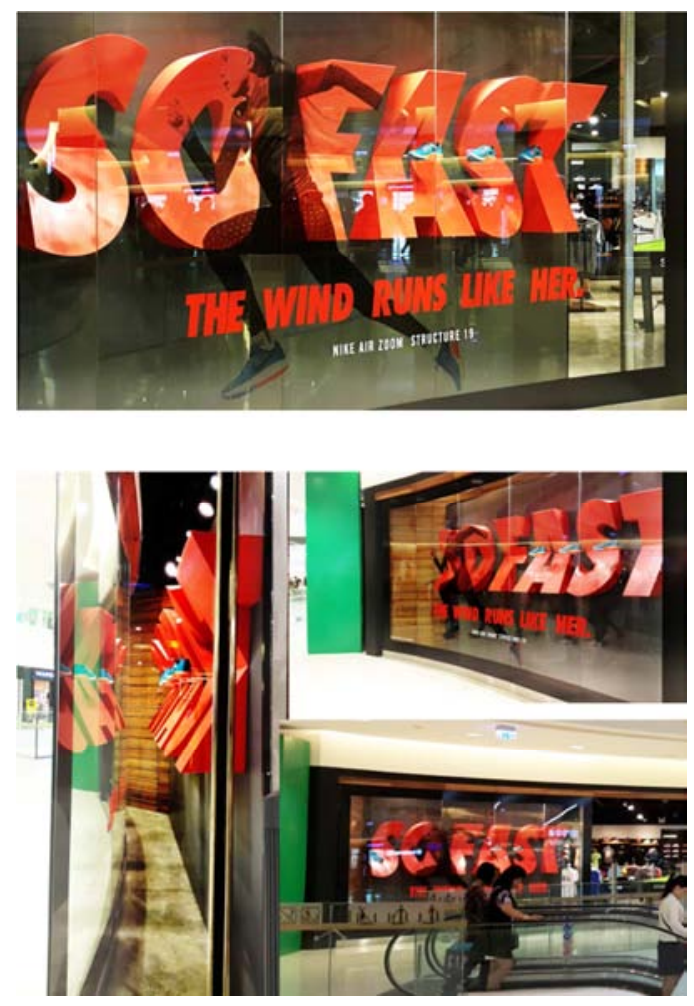

Source of photo: Author, 2017

Figure 9. The fashionable concepts of listening, seeing, touching and non-touching civilization have created a framework for the formation of new design trends of advertising poster such as synthetic, focusing on the directed interactions to human senses in urban environtment. Interaction advertising with the customer. Example, Nike air advertising at Crescent Mall, District 7, Ho Chi Minh City, Vietnam.

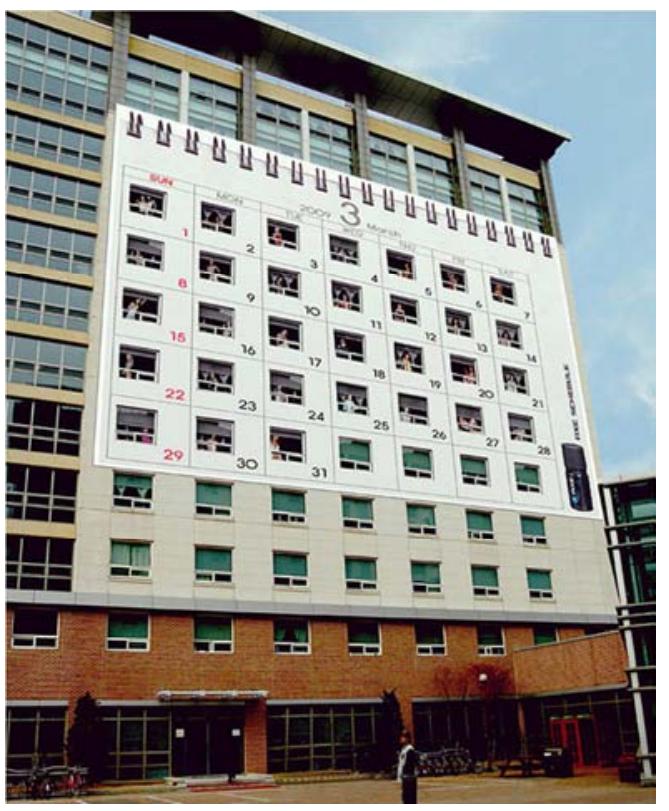

Figure 10. Advertising make the urban environment look more interesting. The windows on building with idea "calendar", it seems to break the normalization of the wall. Example, Fitness Company's Subway Barbell, Seoul, South Korea [13].

Source of photo:

http://www.creativeguerrillamarketing.com/advertising/42-adverts-that-brea k-the-4th-wall/ (8:22 AM, 28 April 2019)

\section{Outdoor Advertising Influenced by Urban Environment Factors Contribute to Orientate Society}

The only purpose of every creation of advertising poster is to draw public attention, to make them like, take into action and make them proud about the choice they've made. Therefore, the aesthetic expression must "awaken" the needs of the public, and those expressions are shown in "postmodern elements" [2]. Advertising poster needs to uphold it's role as an artwork serves for the "life's sake". Advertising poster always begin from the requirements of life in a specific period of time and for a specific space.

Moreover, if advertisers and designers solely focus on maximizing profits without paying attention to social consciousness, advertising will have an adverse effect on potential customers [4]. Beside product quality, outdoor advertising needs to establish aesthetic environment that is in harmony with the material and spiritual needs of everyone. It is closely associated with the development of culture, the civilization of the community in the technological era. It can be said that in today's growing economy, outdoor advertising plays its role as a service of "life's sake".

The need of enjoying culture value in every social class is increasing rapidly and diversely [6]. This means that, according to the law of supplying and demanding, it will stimulate the culture activities and make culture becomes more flexible and efficient. Urban environment elements such as "existentialism, positivism, rationalism, eclecticism" [2] highlighting the reality 
of life, the synthesis of styles in outdoor advertising, etc., have satisfied the high aesthetic demands of the society and affect human senses; they are somehow activate its vocation for exploring, inspiring, making impact and getting involved inspiration from the viewers. Through the valuable artworks, the public is offered knowledge, which gradually help them to raise their level of artistic enjoyment, and then, step-by-step to form an artistic taste.

The trendy view of audiovisual civilization has created a framework for the movement of outdoor advertising design. This trend has the potential to affect the human senses, which help to explore, impress and inspire interaction. Admittedly, the cultural needs of all classes are growing and diversifying. This, in accordance with the rules of supply-demand, stimulates cultural activities and make them more efficient and flexible. Notably, there is an increase in dedicated activities and the importance of aesthetic values in life [8]. In general, the public requires advertising designs that have constant changes in content and presentation. They even need to have their own unique personality. With the motto of bringing beauty into social life, the urban environment in outdoor advertising has been operating creatively in order to create an aesthetic environment that suits the requirements of the society.

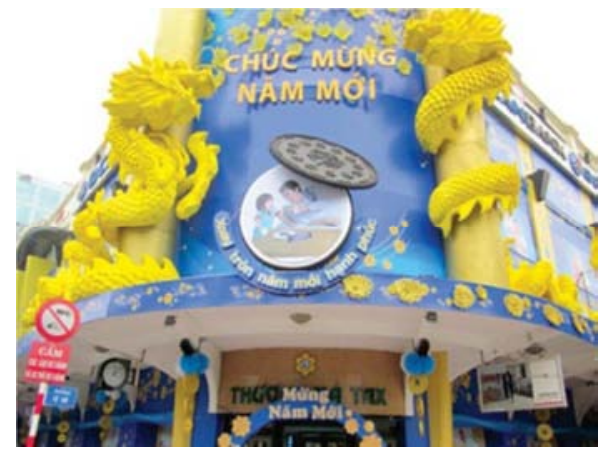

Figure 11. Vietnamese New Year. Building wraps are giant almost billboard-like advertisements that are attached to buildings in order to catch the attention of an audience. Example, Oreo utilizes the corner of the building available to advertising in Ho Chi Minh City, Vietnam [14].

\section{Source of photo:}

http://en.vietnamitasenmadrid.com/2012/01/vietnam-new-years-eve-pictures .html (8:15 AM, 28 April 2019)

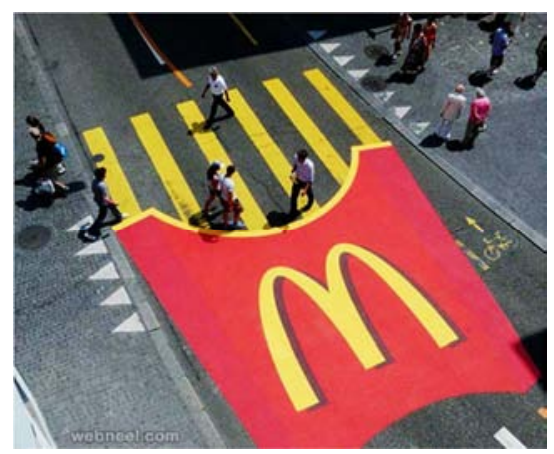

Figure 12. People can interact right on the street. Environmental factors have made art come into life and appear anytime, anywhere.

Source of photo: http://webneel.com/advertising-ideas (7:40 AM, 28 April 2019)



Figure 13. Urban environment fators in the expression of artistic form. The advertising is so larger than life and somewhat out of place that it is almost possible for consumers to notice them, whether they are interested in the product or brand being advertised [15].

Source of photo: http://webneel.com/advertising-ideas (7:59 AM, 28 April 2019)

\section{Results}

Overall, it can be said that outdoor advertising has many advantages over other types of graphic designs, which thanks to visual thinking. In particular, visual thinking is used as a way to convey messages of the product to the target customers. In addition, images and presentation are also employed to recognize information of advertising. They are always sensitive and open to revolutions in the art culture.

Moreover, the bottom line is that every idea in creating outdoor advertising is always closely connected with life. It also needs to be changed to fit contemporary tastes. This contributes to enhancing the role of aesthetic orientation in society, because art is a form used to reflect society and change social perception.

From recognizing the interaction between visual arts and social aesthetics, the article shows the positive aspects that need to be promoted when creating outdoor advertising in the context of the urban environment. Besides, it also mentions the limits that need to be identified in design. By this way, the designs will be highly adaptable to the cultural characteristics and aesthetic transformation trends, which help maximize the target customers - modern citizens.

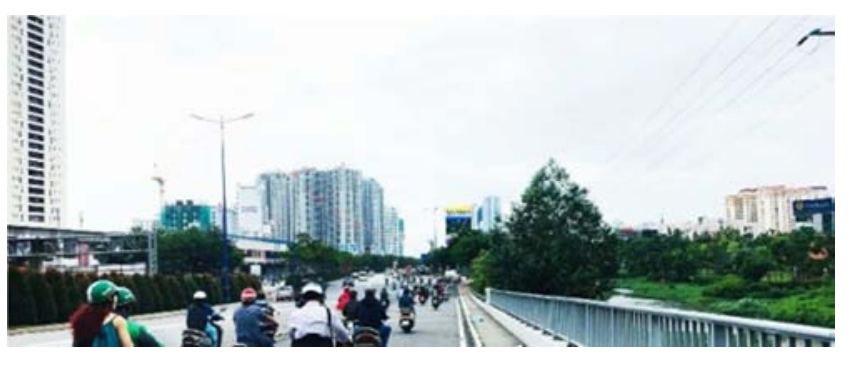

Source of photo: Author, 2018

Figure 14. In District 2, Ho Chi Minh City, Vietnam. 


\section{References}

[1] Nguyen Thi Viet Ha (2018), "Urban Environment Factors in Advertising Poster in Ho Chi Minh City", MATEC Web of Conferences Vol.193, 01020, e-ISSN: 2261-236X, 20 August 2018; https://doi.org/10.1051/matecconf/201819301020

[2] Tran Quang Thai (2011), Postmodernism - Matter of Theory (Chủ Nghĩa Hậu Hiện Đại - Các Vấn Đề Nhận Thức Luận), Tổng Hợp Publishing, Ho Chi Minh City.

[3] Claire Bishop (2011), Installation Art, Tate Publishing.

[4] Bui Van Danh (2007), Matter of Taste and Advertising (Thi Hiếu và Quảng Cáo), Saigon Cultural Publishing.

[5] Max Sutherland (2014), Advertising and public psychology (Quảng cáo và tâm lý công chúng), Now Publishing, Ho Chi Minh City.

[6] Nguyen Thi Hau (2013), Aesthetic of Young People in Ho Chi Minh City (Thị hiếu thẩm mỹ của giới trẻ thành phố Hồ Chí Minh), Art Culture Publishing, Ho Chi Minh City.

[7] Peter Osborne (2011), Conceptual Art, Phaidon Press Ltd.

[8] Chu Quang Tru (2013), Vietnam Cultural from art (Văn hóa Việt Nam nhìn tù mỹ thuật), Art Publishing, Hanoi.

[9] https://www.siemens.com/press/en/presspicture/?press=/en/pre sspicture/2014/corporate/im2014110148coen.htm\&content[]= Corp (8:50 AM, 20 april 2019)

[10] https://www.crookedbrains.net/2010/04/building-advertisemen ts.html (8:42AM, 28 April 2019)

[11] http://theinspirationroom.com/daily/2011/coca-cola-illuminate s-125-years/ (8:35 AM, 28 April 2019)

[12] https://news.zing.vn/video-bang-quang-cao-biet-noi-doc-daopost562072.html (9:00 AM, 16 May 2017)

[13] http://www.creativeguerrillamarketing.com/advertising/42-adv erts-that-break-the-4th-wall/ (8:22 AM, 28 April 2019)

[14] http://en.vietnamitasenmadrid.com/2012/01/vietnam-new-year s-eve-pictures.html (8:15 AM, 28 April 2019)

[15] http://webneel.com/advertising-ideas (7:40 AM, 28 April 2019) 